\title{
Diseño robusto para optimizar un invernadero en el valle del Mantaro
}

\section{Robust design to optimize a greenhouse in the Mantaro valley}

\author{
'Lazo Baltazar, B.D.; Huari Vila, O.P. \\ Facultad de Ingeniería Mecánica / Universidad Nacional del Centro del Perú \\ Email: blazo@uncp.edu.pe
}

\section{Resumen}

El objetivo de la investigación es diseñar un sistema robusto para optimizar un invernadero en el valle del Mantaro. Para lo cual se ubicó el lugar de investigación en la séptima cuadra del Jirón Auquimarca del distrito de Chilca, 12 grados de latitud sur y longitud 75 grados sur. Como resultado, se encontró que los factores más significativos en el invernadero estudiado son: el ángulo de inclinación, la orientación, el tiempo de carga y la estación cuando se realiza las mediciones.

Palabras clave: invernadero, teoría de sistemas, diseño robusto, método Taguchi

\begin{abstract}
The objective of the research is designing a robust system to optimize a greenhouse in the Mantaro Valley. For which the investigation location was located in the seventh block of the Jirón Auquimarca of Chilca district, 12 degrees south latitude and 75 degrees south longitude. As a result, it was found that the most significant factors in the greenhouse studied are: the angle of inclination, the orientation, the loading time and the station when the measurements are made.
\end{abstract}

Keywords: greenhouse, systems theory, robust design, Taguchi method

\section{Introducción}

El método robusto de Taguchi se basa en el diseño y análisis del comportamiento de los factores que gobiernan un sistema, determinando su significancia dentro del sistema.

"Las relaciones señal/ruido (S/N) del Dr. Taguchi, que son funciones de registro, se basan en experimentos de "orthogonal array" que proporcionan una "varianza" muy reducida para el experimento con "configuraciones óptimas" de parámetros de control. Por lo tanto, el matrimonio de diseño de experimentos con la optimización de los parámetros de control para obtener mejores resultados se logra en el método Taguchi. Los "arreglos ortogonales" (Orthogonal Arrays, OA) proporcionan un conjunto de experimentos (mínimos) bien equilibrados y resultados deseados, sirven como funciones objetivas para la optimización, ayudan en el análisis de datos y la predicción de resultados óptimos" (Karna, 2015).

En los últimos años se viene produciendo un aumento notable de agricultura con apoyo de invernaderos, por sus grandes ventajas en el aprovechamiento de la energía solar térmica y lucha contra los friajes que ocasionan grandes pérdidas, existiendo muchas organizaciones que están trabajando arduamente para promover el conocimiento y el desarrollo de una práctica medio ambiental más responsable y, por otra parte, a la continua mejora y reducción de costes de los invernaderos. El presente trabajo de investigación tiene el objetivo de diseñar un sistema robusto para optimizar un invernadero en el valle del Mantaro, cuyo sustento científico se centra en la optimización del funcionamiento de los sistemas poco sensibles a diversos factores. 


\section{Materiales y métodos}

\section{Materiales}

La presente investigación, se realizó en un invernadero construido de 3 x 5 metros. Del mismo modo, se usaron instrumentos de medición como: termómetros, medidores de viento y software especializado de apoyo.

\section{Métodos}

El tipo de investigación es tecnológica, nivel de investigación experimental y método de investigación experimental.

\section{Resultados}

Las variables estudiadas aplicando el método Taguchi, definiendo los niveles de estudio, de manera indistinta cualitativos y cuantitativos.

Tabla 1

Factores de evaluación Plackett - Burman

\begin{tabular}{clcc}
\hline Código & \multicolumn{1}{c}{ Factores controlables } & Nivel 1 & Nivel 2 \\
\hline A & Orientación & Oeste & Norte \\
B & Forma de techo & Elíptico & Dos aguas \\
C & Clima & Nublado & Soleado \\
D & Superficie del invernadero & 12 & 25 \\
E & Altura del invernadero & 3 & 4 \\
F & Humedad relativa & alta & baja \\
G & Velocidad del viento & alta & baja \\
\hline
\end{tabular}

Fuente: Elaboración propia

Luego de hacer las mediciones en base a la matriz Taguchi L8 con tres réplicas.

Tabla $\mathrm{N}^{\circ} 2$

Repuesta para relaciones de señal ruido más grande mejor

\begin{tabular}{cccccccc}
\hline Nivel & A & B & C & D & E & F & G \\
\hline 1 & 24.43 & 24.47 & 27.22 & 26.67 & 25.93 & 26.84 & 27.31 \\
2 & 29.28 & 29.24 & 26.49 & 27.05 & 27.78 & 26.88 & 26.41 \\
Delta & 4.85 & 4.77 & 0.73 & 0.38 & 1.85 & 0.03 & 0.90 \\
Clasificar & 1 & 2 & 5 & 6 & 3 & 7 & 4 \\
\hline
\end{tabular}

Fuente: Elaboración propia

\section{Discusión}

Los factores estudiados en orden de significación en el sistema estudiado se dan en el siguiente orden: $(1-\mathrm{A}-$ orientación $),(2-\mathrm{B}$ - forma de techo $),(3-\mathrm{E}-$ altura de invernadero), (4-G - velocidad de viento), (5- C - Clima), (6 - D - superficie de invernadero), (7 - humedad relativa).

\section{Conclusiones}

- Los factores más significativos en el invernadero son: la orientación, forma de techo y altura de invernadero. Los resultados confirman las exigencias del método F - chart, para los sistemas solares térmicos.

\section{Referencias bibliográficas}

Valera Martínez, D. L., Belmonte Ureña, L. J., Molina Aiz, F. D., \& López Martínez, A. (25 de Julio de 2014). Los invernaderos de Almería: tipología y mecanización del clima. 504. Almería, España: Cajamar Caja Rural. Obtenido de Cajamar Web site: https://www.publicacionescajamar.es/ series-tematicas / economia/los-invernaderos-de-almeria-analisis-de-su-tecnologia-y-rentabilidad

Gutiérrez, H., \& De La Vara, R. (Eds.). (2008). Análisis y diseño de experimentos (Segunda Ed). México: Mc Graw Hill.

Karna, S. K. (2015). An Overview on Taguchi Method An Overview on Taguchi Method, (March).

López, A. \& Benavides, C. (2014). Respuesta térmica del invernadero de la Estación Experimental $\mathrm{Fa}$ bio Baudrit Moreno, Alajuela, Costa Rica, 25(1), 121-132.

Macías, I. Q. D. de experimentos I. M. G. (2008). Diseño de experimentos robusto (Taguchi). Universidad Politécnica Tlaxcala, 6. 